\title{
Gender and Physician differences in the Physician-Patient Discussion Prior to Open Access Colonoscopy
}

\author{
Stacy B. Menees ${ }^{1, *}$, Dana Freeman ${ }^{2}$, David Johnson ${ }^{3}$, Michael Ryan ${ }^{3}$, Jeff Willis ${ }^{3}$, \\ Taylor Wootton ${ }^{3}$, Kelvin Hornbuckle ${ }^{3}$, Whitney Brooks ${ }^{3}$ and James Paulson ${ }^{3}$ \\ ${ }^{1}$ University of Michigan, Division of Gastroenterology 3912 Taubman Center, SPC 5362, Ann Arbor, MI 48109-5362, USA \\ ${ }^{2}$ St. John - Providence Hospital, 16001 West Nine Mile Rd, Southfield, MI 48075, USA \\ ${ }^{3}$ Eastern Virginia Medical School, Department of Internal Medicine, P.O. Box 1980, Norfolk, VA 23501-1980, USA
}

\begin{abstract}
Objective: The purpose of our study was to examine the discussion prior to open access colonoscopy (OAC) to assess for areas of improvement.

Methods: An anonymous questionnaire was administered to consecutive patients undergoing OAC.

Results: 426 subjects completed the questionnaire. Male subjects reported a mean $9.7 \pm 4.3$ minutes of discussion about CRCS, colonoscopy procedure and preparation compared to female subjects at $7.6 \pm 4.3 \mathrm{~min}$. $52 \%$ of participants felt that they were adequately informed prior to OAC. Women were less likely to have discussed other forms of CRCS (OR 0.36, $\mathrm{p}<0.001)$, risks of colonoscopy (OR $0.45, \mathrm{p}=0.005)$ medications to avoid $(\mathrm{OR} 0.51, \mathrm{p}=0.012$ ) and were half as likely to feel adequately informed by their practitioner (OR 0.40, p<0.001). Of all PCPs, women felt that GYNs best informed them about their procedure (OR 12.5, $\mathrm{p}=0.005$ ). Subjects with a relationship for 10 years or greater with their doctor were $43 \%$ more likely to be adequately informed (OR $1.43, \mathrm{p}=0.00)$.

Conclusion: Despite the time devoted by PCPs patients, particularly women, are least likely to feel informed about the CRCS process. With the increasing efforts to improve CRCS compliance, strategies must be developed to prompt PCPs to discuss the CRCS process with their patients.
\end{abstract}

Keywords: Colorectal Cancer, screenings, gender, preventive service, colonoscopy.

\section{INTRODUCTION}

In 2009 , colorectal cancer (CRC) is expected to account for approximately 146,970 new diagnoses and 49,920 deaths in the United States [1]. This accounts for a $>5 \%$ lifetime risk of colorectal cancer in both sexes. Despite recommendations from the American Cancer Society, U.S Multi-society Task force on Colorectal Cancer and the United States Preventive Services Task Force, colorectal cancer screening compliance remains suboptimal [2]. The Behavioral Risk Factor Surveillance Survey found a $60 \%$ adherence rate for all accepted modalities in 2006, markedly lower than that for breast or cervical cancer screening [3].

The majority of CRC screening recommendations are delivered by primary care providers. Data from the 20062007 National Survey of Primary Care Physicians' Recommendations and Practices for Breast, Cervical, Colorectal and Lung Cancer Screening demonstrate that colonoscopy is the most frequently recommended test despite the array of modalities that are available [4]. This practice pattern has changed considerably from 1999-2000 data where fecal occult blood test (FOBT) was the predominantly recommended

*Address correspondence to this author at the 3912 Taubman Center, SPC 5362, Ann Arbor, MI 48109-5362, USA; Tel: 734-232-3739;

Fax: 215310 9751; E-mail: sbartnik@med.umich.edu modality. Mounting evidence demonstrating the efficacy of colonoscopy led to Medicare's declaration of reimbursement for screening colonoscopy in average risk patients aged 50 and older in 2001 [5-7]. With the increased demand for colonoscopy, an open access system bypassing a gastroenterology consult in healthy individuals has been endorsed to help defray the cost of colonoscopy and decrease the wait time for the procedure in hopes of improving CRC screening compliance.

Further evaluation of the pre-procedure discussion prior to open access colonoscopy may help target specific areas to increase CRC screening compliance. Previous studies have shown that there is a limited discussion regarding colon cancer screening between primary care providers and patients $[8,9]$. The aim of our study was to assess the physicianpatient discussion prior to open access colonoscopy in the community setting from the patients' perspective. We planned to determine the length and content of discussion that occurs for open-access colonoscopy and compare discussions between male and female patients.

\section{METHODS}

The study was conducted at a single specialty gastroenterology practice comprised of 8 gastroenterologists and 5 nurse practitioners in Norfolk, Virginia with a practice size 
of approximately 16,000 patients from January 2008 to September 2008. Institutional review board approval was obtained through Eastern Virginia Medical School, which granted a waiver of consent because of the anonymity of data the survey procedure. A one-page cover letter and survey were developed with questions created in a close-ended fashion to maximize response rates. A pilot test of the survey was performed with patient volunteers to ensure comprehension. Consecutive patients referred for open access colonoscopy with the indication of colon cancer screening were solicited while awaiting their procedure. Respondents were instructed by personnel that the study was entirely voluntary and their decision to fill out the survey would not impact their procedure in any way. Staff were available to answer any questions regarding the survey.

Respondents answered a 19 question survey instrument. (Appendix 1) Data obtained included subjects' age, gender, ethnicity, and referring physician type and gender. Patients were asked to specify how many times per year and for how many years they had been seeing their primary care provider. They were asked if this was their first colonoscopy and if their provider discussed the benefits of CRC screening, other CRC screening methods besides colonoscopy, medications to avoid prior to colonoscopy, and the risks of colonoscopy. Subjects listed the number of minutes their referring doctor discussed CRC screening, the colonoscopy procedure and colonoscopy preparation. Additional questions assessed whether the participants felt that they were adequately informed about the colonoscopy procedure, if they had received a handout/brochure about colonoscopy, if they would have preferred an appointment with a gastroenterologist prior to their procedure and what influenced them to have the colonoscopy scheduled.

\section{Statistical Analysis}

A univariate general linear model was utilized to assess the effects on the time (in minutes) that was reported for discussion of various topics. Binary logistic regression was then used to examine how various patient, physician, and historical variables predicted pre-colonoscopy discussion of various topics (all coded as yes/no). In all models, $p$ values < 0.05 were considered significant, and results are presented as regression coefficients and odds ratios, all with $95 \%$ confidence intervals. Data were analyzed using SPSS version 16.

\section{RESULTS}

\section{Demographics}

A total of 431 subjects were approached while awaiting open access colonoscopy, of which 426 subjects completed the questionnaire for a $99 \%$ response rate. Study characteristics are listed in Table 1. Fifty-two percent of the population was female. The majority of participants were Caucasian (70\%), and 22\% were African American. The average age was $52.8( \pm 5.3)$ yrs. Subjects had seen their primary care physicians for $7.9( \pm 7.6)$ yrs and averaged two visits/yr. Sixty-three percent of primary care providers were male. Forty seven percent of referring physicians were family practice, $39.2 \%$ were internists (IM), and $8.9 \%$ were gynecologists. Since most of the physicians were male (64.8\%) and patients demonstrated more gender balance (47.5\% male), female patients were 5.4 times less likely
$(\mathrm{OR}=5.35, \mathrm{p}<.001 ; 95 \%$ CI: 3.38-8.46) than male patients to be matched with a gender-concordant physician.

Table 1. Characteristics of the Study Population

\begin{tabular}{|l|l|}
\hline \multicolumn{1}{|c|}{ Characteristic } & \multicolumn{1}{|c|}{ N\% } \\
\hline \hline Race & $300(91 \%)$ \\
Caucasian & $94(9 \%)$ \\
African American & $13(3.1 \%)$ \\
Asian & $19(4.4 \%)$ \\
\hline Other & \\
\hline Age (years) & $52.8 \pm 5.3$ yrs \\
Mean (SD) & \\
\hline Patient Gender & $223(52 \%)$ \\
Female & $203(48 \%)$ \\
Male & \\
\hline Referring Physician Gender & $269(63 \%)$ \\
Male & $157(37 \%)$ \\
\hline Female & \\
\hline Physician Specialty & $201(47.2 \%)$ \\
Family Medicine & $167(38.2 \%)$ \\
Internal Medicine & $38(8.9 \%)$ \\
Obstetrics/Gynecology & $20(5.7 \%)$ \\
\hline Other & $230(94 \%)$ \\
Preventive Practices & $198(81 \%)$ \\
\hline Mammography & $2.4 \pm 1.7$ \\
\hline PAP smear & $7.9 \pm 7.6$ \\
\hline Average years with PCP & \\
\hline
\end{tabular}

\section{CRC Screening Discussion Length}

Male participants reported a mean $9.7 \pm 4.3$ minutes of discussion about CRC screening, the colonoscopy procedure and preparation compared to women who reported $7.6 \pm 4.3$ min, although this difference was not statistically significant. Female physicians' discussions were reported as not significantly longer than their male cohorts, measuring $11.2 \pm 1.9$ vs. $10.8 \pm 1.9 \mathrm{~min}$, respectively. There were significant differences in reported discussion time between specialties ( $F$ $(3,394)=3.36, \mathrm{p}=.019)$, with family practitioners $(12.6$ $\pm 4.1 \mathrm{~min})$ having significantly more $(\mathrm{p}=.039)$ discussion regarding CRC screening/open access colonoscopy than internal medicine physicians $(7.8 \pm 4.0 \mathrm{~min})$ and marginally more $(\mathrm{p}=.096)$ than gynecologists $(6.7 \pm 4.8 \mathrm{~min})$.

\section{CRC Screening Discussion Content}

Fifty-seven percent of subjects recalled discussing the benefits of CRC screening. Twenty-five percent of subjects discussed alternative CRC screening methods besides colonoscopy. Women were less likely than men to have dis- 
cussed other forms of CRC screening (OR 0.36, $\mathrm{p}<0.001$; 95\% CI: .24-.60).

\section{OAC Procedure Discussion}

Twenty percent of participants reported discussing the risks of open access colonoscopy with their practitioner. Twenty-three percent reported discussing the medications to avoid prior to their open access colonoscopy. Slightly more than half $(52 \%)$ felt that they were adequately informed prior toopen access colonoscopy. However, only $15.6 \%$ of participants would have preferred an appointment with gastroenterology prior to open access colonoscopy. Women were half as likely to be adequately informed by their practitioner (OR $0.40, \mathrm{p}<0.001 ; 95 \% \mathrm{CI}: 0.32-0.72$ ), the risks of colonoscopy (OR $0.45, \mathrm{p}=0.005 ; 95 \% \mathrm{CI}: 0.29-0.77$ ) and medications to avoid (OR 0.51, $\mathrm{p}=0.012$; 95\% CI: $0.35-0.86$ ). Seventy percent of participants reported that they did not receive a handout or brochure regarding the open access colonoscopy procedure.

\section{Referring Physician Factors}

Of all primary care providers, participants felt that gynecologists best informed them about their OAC procedure (OR 9.01, $\mathrm{p}=0.01 ; 95 \%$ CI: 1.61-51.44). Patients listed physician recommendation $(67 \%)$ as the number one reason to undergo open access colonoscopy. Participants with a relationship for 10 years or greater with their physician were $43 \%$ more likely to feel adequately informed (OR 1.43, $\mathrm{p}=0.00 ; 95 \%$ CI: 1.09-2.56). Gynecologists (OR 9.5, $\mathrm{p}=0.005 ; 95 \% \mathrm{CI}: 1.77-40.36)$ and internal medicine doctors (OR 4.3, $\mathrm{p}=0.042 ; 95 \% \mathrm{CI}: 1.02-16.48)$ were most likely to discuss benefits of CRCS with subjects. Female physicians were the most influential in a patient's decision to undergo a colonoscopy (OR 1.63, p=0.04; 95\% CI: 1.01-2.58).

\section{DISCUSSION}

Open access colonoscopy is a modality utilized by primary care providers to reduce the risk of CRC in their patients. With improved availability through open access referral and continued CRC screening education, overall CRC screening adherence is slowly improving, although remains significantly lower to breast and cervical cancer screening [3]. This study examined the pre-procedure discussion prior to open access colonoscopy, focusing on the time spent discussing CRC screening and open access colonoscopy particularly related to gender and referring provider characteristics. Our findings demonstrate that despite a mean discussion time of 7.5 minutes or more, only slightly $>50 \%$ felt adequately informed prior to their procedure. This finding underscores the importance of physician recommendation; as a significant driving force in CRC screening despite not feeling adequately informed about open access colonoscopy. Physician recommendation in our population was the number one reason for undergoing open access colonoscopy. This corresponds to previous studies citing physician recommendation as an important factor influencing a patient decision to undergo CRC screening [10-16]. To improve future open access colonoscopy patient education and thus increase patient adherence, we must ensure patient reception of an open access colonoscopy handout that would explain the value of open access colonoscopy in preventing CRC, the actual procedure and address frequently asked questions. Denberg et al. demonstrated an improvement of 11.7 percentage points in colonoscopy adherence in patients receiving an educational brochure for on CRC screening and colonoscopy, yet $70 \%$ of participants in our study failed to receive this [17]. Other studies have demonstrated that patients' interest in undergoing cancer screening increases once they received information [18-23]. Therefore, continuing to target primary care and gastroenterology providers for practice-based improvements for in OAC for CRC screening is critical.

Overall, female patients had felt less well informed about open access colonoscopy than did men and were less likely to have discussed alternative forms of CRC screening, and feel adequately informed by their practitioner of the risks of colonoscopy and medications to avoid. The reasons for the above are unknown. One may hypothesize that embarrassment in discussing open access colonoscopy may account for this as women have associated embarrassment with flexible sigmoidoscopy and colonoscopy [24, 25]. Women in this study were also less likely to have gender concordant physicians as the majority of our practitioners were male. Due to lack of gender concordant physician, women may be less inclined to ask questions about open access colonoscopy and talk to their male practitioners. Previously, Kerssens et al. demonstrated that women felt that they talked more easily to female than to male health professionals [26].

In past studies, gynecologists have been shown to be less likely to recommend CRC screening than internists and family practitioners $[27,28]$. In a 2006 survey of gynecologists and nurse practitioners, FOBT $(76.2 \%)$ was the preferred CRC screening modality compared to colonoscopy $(28.3 \%)$ [29]. However American College of Obstetrics \& Gynecology (ACOG) announced new recommendations in October 2007, emphasizing colonoscopy as the preferred method for CRC screening. This recommendation may have impacted our study [30]. We suspect that recent education on CRC screening and colonoscopy due to the ACOG announcement impacted our study, as gynecologists' best informed their patients about open access colonoscopy and CRC screening benefits.

Female physicians also were the most influential in our participants' decision to undergo a colonoscopy. This correlates with previous studies demonstrating that female physicians were far more likely to recommend CRC screening than their male counterparts $[31,32]$. Additionally, in a retrospective series of patients undergoing upper endoscopy, having a female physician was associated with increased prevalence of CRC screening at the time of upper endoscopy and increased CRC screening completion in the 6 months afterward [33]. Our finding also corresponds to other preventive health behaviors. Data from the gynecologic and primary care literature demonstrate that patients of female physicians are also more likely to undergo breast and cervical cancer screening than patients of male physicians $[34,35]$.

Our study has some potential limitations. The primary limitation of our study is that it relied on participant selfreport; therefore, recall bias may have been introduced. Participants may have over/underestimated the discussion time and may have incorrectly recalled their CRC screening discussions with their providers. However, in some case patient 
report has been shown to be more reliable than the medical record. The medical record may under-document counseling and educational advice $[36,37]$. There may be a demographic bias of our population since the majority of our population was Caucasian. Therefore, our findings may not be generalized to other ethnic groups. Our study was crosssectional in nature and thus precludes causal inferences. Lastly, close to $50 \%$ of our respondents' physicians were family practitioners and this may have skewed our results when evaluating physician behaviors.
Despite the time devoted by PCPs, patients do not feel well informed about open access colonoscopy and CRC screening. Specifically, women are least likely to feel informed about the CRC screening process. Female physicians had the most impact on the decision to undergo open access colonoscopy. In continuing to improve CRC screening compliance, additional strategies must be in place to prompt PCPs to discuss the CRCS process with their patients.

\section{APPENDIX 1}

1. Please check the gender of the doctor who referred you:

\section{Male}

Female

2. Please check the type of doctor who referred you:

\section{Family Practice}

Internal Medicine

Obstetrics/Gynecology

Other: (please list)

3. Please list your age in years:

4. Ethnic group (please check all that apply)

\section{Caucasian}

Asian

Black or African-American

American Indian/Alaska Native

Latino or Hispanic

5. Please check your gender:

Male

Female

6. How many times per year do you see your primary care doctor?

7 . How many years have you been seeing your primary care doctor?

8. Is this the first time you are undergoing a colonoscopy?

Yes

No (Please list how many previous times

9. Did your referring doctor discuss other colon cancer screening methods such as stool tests, barium enema or flexible sigmoidoscopy with you?

\section{Yes}

No

10. Please list the number of minutes that your referring doctor discussed colorectal cancer screening.

11. Please list the number of minutes that your doctor discussed the colonoscopy procedure that you are having today.

12. Please list the number of minutes that your referring doctor discussed what was involved in preparing for the colonoscopy.

13. Did your doctor discuss the benefits of CRC screening?

\section{Yes}

No 
Appendix 1. contd....

14. Did your doctor discuss medications that you were to avoid prior to the colonoscopy?

Yes

No

15. Did your doctor discuss the risks of the colonoscopy procedure such as perforation or bleeding?

Yes

No

16. Do you believe you were adequately informed about the colonoscopy procedure?

Yes

No

17. Did you receive a handout or other type of brochure on the colonoscopy procedure?

Yes

No

18. Would you have liked an appointment with a gastroenterologist before your procedure to further explain the colonoscopy procedure and preparation?

Yes

No

19. What influenced you the most to get this procedure done?

My doctor recommended it

I have a family member with polyps or colon cancer

My family

Newspaper, TV publicity (Katie Couric)

Other, Please List

\section{REFERENCES}

[1] Jemal A, Siegel R, Ward E, Hao Y, Xu J, Thun MJ. Cancer statistics. CA Cancer J Clin 2009; 59(4): 225-49.

[2] Levin B, Lieberman D, McFarland B, et al. Screening and surveillance for the early detection of colorectal cancer and adenomatous polyps, a joint guideline from the American Cancer Society, the US Multi-Society Task Force on Colorectal Cancer, and the American College of Radiology. CA Cancer J Clin 2008; 58(3): 130-60.

[3] Centers for Disease Control \& Prevention (CDC). Use of colorectal cancer tests--United States, 2002, 2004, and 2006. Morb Mortal Wkly Rep 2008; 57(10): 253-8.

[4] Klabunde CN, Lanier D, Nadel MR, McLeod C, Yuan G, Vernon SW. Colorectal cancer screening by primary care physicians: recommendations and practices, 2006-2007. Am J Prev Med 2009; 37(1): 8-16.

[5] Winawer SJ, Zauber AG, Ho MN, et al. Prevention of colorectal cancer by colonoscopic polypectomy. The National Polyp Study Workgroup. N Engl J Med 1993; 329(27): 1977-81.

[6] Citarda F, Tomaselli G, Capocaccia R, Barcherini S, Crespi M. Efficacy in standard clinical practice of colonoscopic polypectomy in reducing colorectal cancer incidence. Gut 2001; 48(6): 812-5.

[7] Thiis-Evensen E, Hoff GS, Sauar J, Langmark F, Majak BM, Vatn MH. Population-based surveillance by colonoscopy: effect on the incidence of colorectal cancer. Telemark Polyp Study I. Scand J Gastroenterol 1999; 34(4): 414-20.

[8] Canada RE, Turner B. Talking to patients about screening colonoscopy--where conversations fall short. J Fam Pract 2007; 56(8): E1-9.
[9] Denberg TD, Melhado T, Coombes JM, et al. Predictors of nonadherence to screening colonoscopy. J Gen Intern Med 2005; 20(11): 989-95.

[10] Griffith KA, McGuire DB, Royak-Schaler R, Plowden KO, Steinberger EK. Influence of family history and preventive health behaviors on colorectal cancer screening in African Americans. Cancer 2008; 113(2): 276-85.

[11] Brawarsky P, Brooks DR, Mucci LA, Wood PA. Effect of physician recommendation and patient adherence on rates of colorectal cancer testing. Cancer Detect Prev 2004; 28(4): 260-8.

[12] Mandelson MT, Curry SJ, Anderson LA, et al. Colorectal cancer screening participation by older women. Am J Prev Med 2000; 19(3): 149-54.

[13] Lewis SF, Jensen NM. Screening sigmoidoscopy. Factors associated with utilization. J Gen Intern Med 1996; 11(9): 542-4.

[14] Kelly RB, Shank JC. Adherence to screening flexible sigmoidoscopy in asymptomatic patients. Med Care 1992; 30(11): 1029-42.

[15] Myers RE, Trock BJ, Lerman C, Wolf T, Ross E, Engstrom PF. Adherence to colorectal cancer screening in an HMO population. Prev Med 1990; 19(5): 502-14.

[16] Weitzman ER, Zapka J, Estabrook B, Goins KV, et al. Risk and reluctance: understanding impediments to colorectal cancer screening. Prev Med 2001; 32(6): 502-13.

[17] Denberg TD, Coombes JM, Byers TE, et al. Effect of a mailed brochure on appointment-keeping for screening colonoscopy: a randomized trial. Ann Intern Med 2006; 145(12): 895-900.

[18] Wagner TH. The effectiveness of mailed patient reminders on mammography screening: a meta-analysis. Am J Prev Med 1998; 14(1): 64-70. 
[19] Vernon SW. Participation in colorectal cancer screening: a review. J Natl Cancer Inst 1997; 89(19): 1406-22.

[20] Taylor VM, Hislop TG, Jackson JC, et al. A randomized controlled trial of interventions to promote cervical cancer screening among Chinese women in North America. J Natl Cancer Inst 2002; 94(9): 670-7.

[21] Richardson JL, Mondrus GT, Danley K, Deapen D, Mack T.Impact of a mailed intervention on annual mammography and physician breast examinations among women at high risk of breast cancer. Cancer Epidemiol Biomarkers Prev 1996; 5(1): 71-6.

[22] Wardle J, Williamson S, McCaffery K, et al. Increasing attendance at colorectal cancer screening: testing the efficacy of a mailed, psychoeducational intervention in a community sample of older adults. Health Psychol 2003; 22(1): 99-105.

[23] Pignone MP, Bucholtz D, Harris R. Patient interest and preferences for colon cancer screening. J Gen Intern Med 1998; 13(supp 1): 96.

[24] Menees SB, Inadomi JM, Korsnes S, Elta GH. Women patients' preference for women physicians is a barrier to colon cancer screening. Gastrointest Endosc 2005; 62(2): 219-23.

[25] Farraye FA, Wong M, Hurwitz S, et al. Barriers to endoscopic colorectal cancer screening: are women different from men? Am J Gastroenterol 2004; 99(2): 341-9.

[26] Kerssens, JJ, Bensing JM, Andela MG. Patient preference for genders of health professionals. Soc Sci Med 1997; 44(10): 1531-40.

[27] Lewis JD, Asch DA, Ginsberg GG, et al. Primary care physicians' decisions to perform flexible sigmoidoscopy. J Gen Intern Med 1999; 14(5): 297-302.

[28] Hawley ST, Levin B, Vernon SW. Colorectal cancer screening by primary care physicians in two medical care organizations. Cancer Detect Prev 2001; 25(3): 309-18.
[29] Menees SB, Patel DA, Dalton V. Colorectal cancer screening practices among obstetrician/gynecologists and nurse practitioners. J Womens Health (Larchmt) 2009; 18(8): 1233-8.

[30] ACOG Committee Opinion No. 384 November 2007: colonoscopy and colorectal cancer screening and prevention. Obstet Gynecol 2007; 110(5): 1199-202.

[31] Shokar NK, Nguyen-Oghalai T, Wu H. Factors associated with a physician's recommendation for colorectal cancer screening in a diverse population. Fam Med 2009; 41(6): 427-33.

[32] Borum ML. Cancer screening in women by internal medicine resident physicians. South Med J 1997; 90(11): 1101-5.

[33] Menees SB, Scheiman J, Carlos R, Mulder A, Fendrick AM, et al. Gastroenterologists utilize the referral for EGD to enhance colon cancer screening more effectively than primary care physicians. Aliment Pharmacol Ther 2006; 23(7): 953-62.

[34] Lurie N, Margolis KL, McGovern PG, Mink PJ, Slater JS. Why do patients of female physicians have higher rates of breast and cervical cancer screening? J Gen Intern Med 1997; 12(1): 34-43.

[35] Henderson JT, Weisman CS. Physician gender effects on preventive screening and counseling: an analysis of male and female patients' health care experiences. Med Care 2001; 39(12): 128192.

[36] Wilson A, McDonald P. Comparison of patient questionnaire, medical record, and audio tape in assessment of health promotion in general practice consultations. Br Med J 1994; 309(6967): 1483-5.

[37] Callahan EJ, Bertakis KD. Development and validation of the Davis Observation Code. Fam Med 1991; 23(1): 19-24.

(C) Menees et al.; Licensee Bentham Open.

This is an open access article licensed under the terms of the Creative Commons Attribution Non-Commercial License (http://creativecommons.org/licenses/ by-nc/3.0/) which permits unrestricted, non-commercial use, distribution and reproduction in any medium, provided the work is properly cited. 